\title{
Conditional Forebrain Inactivation of Nicastrin Causes Progressive Memory Impairment and Age-Related Neurodegeneration
}

\author{
Katsuhiko Tabuchi, ${ }^{1,2 \star}$ Guiquan Chen, ${ }^{3 \star}$ Thomas C. Südhof, ${ }^{1,2}$ and Jie Shen ${ }^{3}$ \\ ${ }^{1}$ Department of Molecular and Cellular Physiology, and Howard Hughes Medical Institute, Stanford University School of Medicine, Palo Alto, California \\ 94304-5543, ${ }^{2}$ Department of Neuroscience and Molecular Genetics, and Howard Hughes Medical Institute, University of Texas Southwestern Medical \\ Center, Dallas, Texas 75390, and ${ }^{3}$ Center for Neurologic Diseases, Brigham and Women's Hospital, Program in Neuroscience, Harvard Medical School, \\ Boston, Massachusetts 02115
}

\begin{abstract}
Loss of presenilin function in adult mouse brains causes memory loss and age-related neurodegeneration. Since presenilin possesses $\gamma$-secretase-dependent and -independent activities, it remains unknown which activity is required for presenilin-dependent memory formation and neuronal survival. To address this question, we generated postnatal forebrain-specific nicastrin conditional knock-out (cKO) mice, in which nicastrin, a subunit of $\gamma$-secretase, is inactivated selectively in mature excitatory neurons of the cerebral cortex. nicastrin cKO mice display progressive impairment in learning and memory and exhibit age-dependent cortical neuronal loss, accompanied by astrocytosis, microgliosis, and hyperphosphorylation of the microtubule-associated protein Tau. The neurodegeneration observed in nicastrin cKO mice likely occurs via apoptosis, as evidenced by increased numbers of apoptotic neurons. These findings demonstrate an essential role of nicastrin in the execution of learning and memory and the maintenance of neuronal survival in the brain and suggest that presenilin functions in memory and neuronal survival via its role as a $\gamma$-secretase subunit.
\end{abstract}

\section{Introduction}

Alzheimer's disease (AD) is an age-related neurodegenerative disorder characterized by progressive memory decline, neuronal loss, and formation of amyloid plaques and neurofibrillary tangles (Price et al., 1998). Dominantly inherited mutations in presenilin (PS) genes, PS1 and PS2, are the primary cause of familial AD (Hardy and Selkoe, 2002). PS forms the $\gamma$-secretase complex together with three other subunits: nicastrin, presenilin enhancer 2 (Pen-2), and anterior pharynx defective 1 (Aph-1) (Fortini, 2002). Although the amyloid precursor protein (APP) and Notch receptors are the physiological substrates of $\gamma$-secretase, additional substrates have been reported, making it difficult to discern which substrate(s) are the key mediator(s) of PS functions (Brown et al., 2000; Fortini, 2002). Furthermore, evidence has also indicated that PS displays $\gamma$-secretase-independent activities, including regulation of $\beta$-catenin signaling and control of calcium release from the endoplasmic reticulum (Kang et al., 1999, 2002; LaFerla, 2002; Tu et al., 2006).

Received March 18, 2009; revised May 5, 2009; accepted May 7, 2009.

This work was supported by a grant from the National Institutes of Health (NS042818;J.S., T.C.S.). K.T. generated floxed nicastrin mice and produced Figure 1A-D. G.C. produced the remaining figures. We thank P. Davis for PHF-1 antibodies, members of the Shen Laboratory for helpful discussions, Xiaoyan Zou and Huailong Zhao for excellent technical assistance, and Dr. Carlos Saura for technical advice on the stereological counting method.

*K.T. and G.C. contributed equally to this work.

Correspondence should be addressed to Dr. Jie Shen, Center for Neurologic Diseases, Brigham and Women's Hospital, Program in Neuroscience, Harvard Medical School, Boston, MA 02115. E-mail: jshen@rics.bwh. harvard.edu.

DOI:10.1523/JNEUROSCI.1320-09.2009

Copyright $\odot 2009$ Society for Neuroscience $\quad 0270-6474 / 09 / 297290-12 \$ 15.00 / 0$
Our previous studies demonstrated that conditional inactivation of PSs in the mouse postnatal forebrain results in synaptic dysfunction and impaired learning and memory, followed by age-dependent neuronal loss (Beglopoulos et al., 2004; Saura et al., 2004). It was, however, unclear whether PS maintains memory formation and promotes neuronal survival via its function as a $\gamma$-secretase subunit. This question is particularly topical in view of recent studies suggesting that PS may act as a calcium leak channel in the endoplasmic reticulum in a $\gamma$-secretaseindependent manner (Tu et al., 2006; Bezprozvanny and Mattson, 2008).

Like presenilin, nicastrin is a subunit of the $\gamma$-secretase complex (Yu et al., 2000). Nicastrin is a type-1 transmembrane glycoprotein that binds to $\gamma$-secretase substrates such as APP and Notch receptors (Yu et al., 2000; Chen et al., 2001) and is required for the cleavage of $\gamma$-secretase substrates (Chung and Struhl, 2001; Edbauer et al., 2002; Hu et al., 2002; López-Schier and St. Johnston, 2002). Nicastrin germline knock-out (-/-) mice die before embryonic day 10.5 (Li et al., 2003a,b; Nguyen et al., 2006). Fibroblasts derived from nicastrin ${ }^{-1-}$ embryos are unable to produce $\mathrm{A} \beta$ peptides and fail to release the intracellular domain of APP and Notch1 (Li et al., 2003a). Nicastrin probably functions as a "recruiter" protein for substrates by binding to their N-terminal free stub (Shah et al., 2005). However, the physiological role of $\gamma$-secretase, in general, and of nicastrin, in particular, in the adult brain remains unknown.

Here, we generated floxed nicastrin mutant mice and crossed them with transgenic mice expressing Cre recombinase under control of the $\alpha$-calcium-calmodulin-dependent kinase II ( $\alpha$ - 
CaMKII ) promoter to obtain postnatal forebrain-specific nicastrin conditional knock-out (cKO) mice (Yu et al., 2001). Levels of PS and Pen-2 are significantly reduced, whereas the C-terminal fragments of APP (APP-CTFs) accumulate in the nicastrin cKO cerebral cortex. Nicastrin cKO mice exhibit progressively impaired learning and memory. Furthermore, nicastrin cKO mice display age-related neuronal and synaptic loss, accompanied by progressive gliosis. The progressive neuronal loss is likely attributable to apoptotic cell death, as evidenced by increased numbers of apoptotic cells in nicastrin cKO mice.

\section{Materials and Methods}

Generation of nicastrin $c K O$ mice. A $17 \mathrm{~kb}$ mouse genomic clone encompassing exons 1-8 of nicastrin gene was isolated from 129/SVJ mouse genomic library and subcloned into NotI site of pBluescriptII KS(-) for the targeting vector. The MulI site between exons 2 and 3 was mutated to introduce a BstI site where a neomycin resistance cassette (NEO), surrounded by flipase recognition target (FRT) and loxP site, was inserted for positive selection. Another loxP flanked by BamHI site was inserted into SmaI site between exons 3 and 4 to allow conditional removal of exon 3 . A diphtheria toxin cassette (DT) was attached to $3^{\prime}$ end of the construct for negative selection. AscI site was introduced outside of $D T$ for linearization of the targeting vector. R1 embryonic stem cells (ES cells) were electroporated with the targeting vector, and cell clones resistant to positive and negative selection were screened by Southern analysis using a $3^{\prime}$ outside probe to detect a size shift by BamHI digestion. Homologously recombined clones were isolated and injected into blastocysts of C57BL/6 mice to generate chimeric mice. Germline transmission was screened by PCR for detecting size shift by loxP insertion between exons 3 and 4 using primer 1, AGCTCTTCACCAGGTAAGAAC, and primer 2, CTTCAGGGAAGGACTGTCCAA. The neomycin resistance cassette (NEO) was removed by flipase recombination by crossing with flipase transgenic mice (fnicastrin mice).

The generation of $\alpha C a M K I I-C r e$ transgenic mice was described previously (Yu et al., 2001). To obtain forebrain-specific nicastrin cKO (fnicastrin/fnicastrin;CaM-Cre or fnicastrin/nicastrin ${ }^{\Delta} ; \mathrm{CaM}-\mathrm{Cre}$ ) mice, we crossed floxed nicastrin (fnicastrin/fnicastrin) mice with $\alpha$ CaMKIICre Tg mice. Homozygous fnicastrin/fnicastrin mice were generated in C57BL/6129 hybrid background, whereas $\alpha$ CaMKII-Cre transgenic mice were generated in C57BL/6CBA hybrid strain and then backcrossed to B6 for $>10$ generations. Therefore, the genetic background of all the mice used in this study was C57BL/6129 hybrid. PS double conditional knockout (PS cDKO) mice were reported previously (Saura et al., 2004). The experimenters of molecular, behavioral, and morphological studies were blind to the genotypes of the mice.

Lentivirus production. Lentivirus vectors carrying either nuclear localization signal (NLS)-EGFP or EGFP-NLS-Cre recombinase fusion gene (Ho et al., 2006) were transfected into HEK293T cells together with the HIV-1 packaging vector 8.9, and the VSVG (vesicular stomatitis virus glycoprotein) envelope glycoprotein using FuGENE6 reagent. Transfected cells were cultured for $48 \mathrm{~h}$ in MEF media or neuron culture medium. Supernatants were filtrated with $0.48 \mu \mathrm{m}$ filter unit and stored at $-80^{\circ} \mathrm{C}$ until use.

Generation of nicastrin $^{-/-}$cell lines. Embryonic day 13.5 embryos were removed from uteri and placed into PBS in Petri dishes. Heads, livers, and hearts were removed, and remains were minced into small pieces. They were then transferred into $1.5 \mathrm{ml}$ Eppendorf tubes. A total of $0.2 \mathrm{ml}$ of $1 \times$ trypsin/EDTA was added and incubated at $37^{\circ} \mathrm{C}$ for $10 \mathrm{~min}$. One milliliter of MEF media (DMEM, 20\% fetal bovine serum, $2 \mathrm{~mm}$ glutamine, $0.1 \mathrm{~mm}$ nonessential amino acids, $1 \mathrm{~mm}$ sodium pyruvate, 50 $\mu \mathrm{g} / \mathrm{ml}$ penicillin/streptomycin, $0.00007 \% \quad \beta$-mercaptoethanol) was added to inactivate trypsin followed by pipetting to dissociate the cells. Cells were transferred into six-well dishes and cultured in $4 \mathrm{ml}$ of MEF media at $37^{\circ} \mathrm{C}$. When cells became confluent [ $\sim 2 \mathrm{~d}$ in vitro (DIV2)], they were trypsinized and transferred into $10 \mathrm{~cm}$ dishes. Small aliquots were kept for genotyping. fnicastrin/ - cells were immortalized by transfection with pCMV-SV40 large-T antigen using FuGENE6. Nicastrin KO cell lines $(-/-)$ were generated from fnicastrin/ - cell lines by Cre recombination using Cre-expressing lentivirus.

Neuron cultures. Hippocampi were dissected from newborn floxed nicastrin mice and minced into small pieces. They were treated with 5 $\mathrm{mg} / \mathrm{ml}$ trypsin for $10 \mathrm{~min}$ at $37^{\circ} \mathrm{C}$ after several washes with HBSS. Trypsin was washed out with HBSS plus 20\% FBS solution and replaced with plating medium (MEM high-glucose medium containing 10\% FBS, transferrin, and insulin). Neurons were dissociated in the plating media by trituration with siliconized Pasteur pipettes and plated on Matrigelcoated coverslips in 24-well plates. They were cultured in similar medium containing B-27 supplement and $4 \mu \mathrm{M}$ cytosine arabinoside to suppress glial growth at $37^{\circ} \mathrm{C}$ in a humidified incubator gassed with $95 \%$ air and $5 \% \mathrm{CO}_{2}$. One-half volume of medium was replaced with viruscontaining media at DIV4. DIV14 cultures were harvested for Western analysis.

Stereology. Brains were perfused with PBS, fixed in $10 \%$ formalin, processed for paraffin embedding, and serially sectioned $(10 \mu \mathrm{m})$. Sagittal brain sections were deparaffinized, alcohol dehydrated, and stained with $0.5 \%$ cresyl violet (Nissl) or immunostained with monoclonal antibodies raised against microtubule-associated protein 2 (MAP2) (1:200; Sigma-Aldrich), synaptophysin (1:200; Sigma-Aldrich), glial fibrillary acidic protein (GFAP) (1:500; Sigma-Aldrich), and incubated with either Alexa Fluor 488 goat anti-mouse or Alexa Fluor 594 goat anti-mouse secondary antibodies (Invitrogen), and then analyzed with a Zeiss 510 confocal laser-scanning microscope. Neuron counts were performed using the optical dissector technique (West and Gundersen, 1990) in $10 \mu \mathrm{m}$ paraffin sagittal sections stained with cresyl violet. Neuronal number and volume of a neocortical hemisphere were determined as described previously (Saura et al., 2004).

Immunoblotting. The mice cortices were dissected and homogenized in cold radioimmunoprecipitation assay lysis buffer [consisting of the following (in mM): $20 \mathrm{~mm}$ Tris- $\mathrm{HCl}, \mathrm{pH} 7.4,150 \mathrm{~mm} \mathrm{NaCl}, 1 \mathrm{~mm}$ EDTA, $1 \%$ NP- $40,0.5 \%$ sodium deoxycholate, and $0.1 \%$ SDS] containing protease and phosphatase inhibitors (Sigma-Aldrich). Lysates were cleared by centrifugation (12,000 rpm for $15 \mathrm{~min}$ ). Normalized volumes of samples were resolved in $4-12 \%$ SDS-PAGE, transferred to nitrocellulose membrane, and immunoblotted using infrared dye-coupled secondary antibodies (goat anti-rabbit IRdye800, goat anti-mouse IRdye680, goat anti-rabbit IRdye680, and goat anti-mouse IRdye800 from Li-Cor). Image acquisition and data quantitation were performed using Odyssey Infrared Imaging System (Li-Cor). Primary antibodies used were as follows: anti-nicastrin (N1660; 1:500; Sigma-Aldrich), anti-PS1-CTF (1: 1000; Millipore Bioscience Research Reagents), anti-PS1-NTF (1:8000; Millipore Bioscience Research Reagents), anti-Pen-2 (1:200; Zymed), anti-Aph-1a (1:200; Zymed), anti-APP (C8; 1:1000), anti- $\alpha$ APPs (1:1000), anti-GFAP (1:500; Sigma-Aldrich), anti-Ibal (1:1000; Wako), anti-VCP (valosin-containing protein) (1:200; Santa Cruz), and anti- $\beta$ actin (1:30,000; Abcam).

TUNEL staining. The brain sections were blocked using $5 \%$ of goat serum for $30 \mathrm{~min}$ followed by the treatment of fluorescein (Roche) at $37^{\circ} \mathrm{C}$ for an hour. The slides were then washed using TBS for three times. Terminal deoxynucleotidyl transferase-mediated biotinylated UTP nick end labeling (TUNEL) staining was analyzed using a Zeiss 510 confocal laser-scanning microscope.

The Morris water maze. The water maze is a circular pool $(160 \mathrm{~cm}$ in diameter). During the hidden platform training, the platform $(10 \mathrm{~cm}$ in diameter) was kept submerged under water and maintained in the same position. Mice were given six trials of training per day (two trials per block; $\sim 2 \mathrm{~h}$ interblock interval) for $7 \mathrm{~d}$, and they were released from all four quadrants in a pseudorandom manner. During the $60 \mathrm{~s}$ training period, if the mice were unable to locate the hidden platform, they were guided to the platform by hand and allowed to remain on it for $30 \mathrm{~s}$. The swimming of the mice was monitored using an automated tracking system (HVS Image). After training days 5 and 7 , the mice were subjected to a 60 s probe trial in which the platform was removed and the mice were allowed to search for it. Ideally, the mice should be released from all four quadrants in a pseudorandom manner during the probe trial, but we released all mice from the opposite quadrant, since the number of mice we had per genotype was not an exact multiple of 4 (for four quadrants). 
In addition, our previous studies using both methods resulted in similar conclusions (Yu et al., 2001; Saura et al., 2004). In the visible platform test, the platform was raised above water and marked by a black-and-white golf ball.

Contextual fear conditioning. For contextual fear conditioning, on training day, mice were placed within the conditioning chamber for 3 min before the onset of the unconditioned stimulus (footshock). After a $1 \mathrm{~s} / 1 \mathrm{~mA}$ single footshock, they were allowed to remain in the chamber for an additional $2 \mathrm{~min}$ and then returned to their home cages. Mice were tested $24 \mathrm{~h}$ after training for $4 \mathrm{~min}$ in the same conditioning chamber. Mice from all genotype groups responded to the footshock similarly by jumping and vocalization. Freezing was defined as a complete cessation of movement except for respiration and scored by an automated system (Actimetrics).

Open field test. VersaMax system from AccuScan Instruments (Columbus Instruments) was used to study locomotor functions of the mice. Two $42 \times 42 \mathrm{~cm}$ Plexiglas chambers were set in a quiet laboratory room. The open-field chamber is divided by 16 horizontal infrared beams from left to right, 16 horizontal infrared beams from front to back on the floor. The mice were allowed to get habituated in the experimental room for $30 \mathrm{~min}$ before the test started. During the test, the mouse was placed in the center of the open-field chamber and allowed to ambulate in it for $15 \mathrm{~min}$. After each testing trial, the chambers were thoroughly cleaned to remove any odors left by animals tested in a previous trial. Movements of the animals were tracked by the VersaMax system.

Rotarod test. The mice were placed in a neutral position on a stationary 6-cm-diameter accelerating rotarod (Economex; Columbus Instruments), which is equipped with individual timers and allows four mice to be tested at a time. Mice were first trained to stay on the rod at a constant rotation speed of $5 \mathrm{rpm}$. Mice unable to stay on the rod for 2 min were placed back on the rod until they did not fall from the rod for 2 min (pretraining). After successful pretraining, mice were placed back on the rod at a rotation speed of $5 \mathrm{rpm}$. The rotating speed is then increased at a rate of $0.2 \mathrm{rpm} / \mathrm{s}$. The latency to fall was measured. All mice were tested for three trials in total on the same experimental day.

Data analysis. Statistical analyses were performed using ANOVA to measure genotype, age effect or genotype by age interaction effect. Two-tailed Student's $t$ test was conducted for all the pairwise comparisons in the behavioral and biochemical results. Unless otherwise stated, three to six mice were used per genotype group. A value of $p<0.05$ is considered significant. All the data were reported as mean \pm SEM throughout.

\section{Results}

\section{Generation of postnatal forebrain-restricted nicastrin} cKO mice

To inactivate nicastrin selectively in the postnatal forebrain, we first generated floxed nicastrin mice, in which exon 3 is flanked by two loxP sites (Fig. 1A). We introduced a $\operatorname{lox} P$ sequence into intron 3 and another loxP site together with a selection cassette,

B

$E$
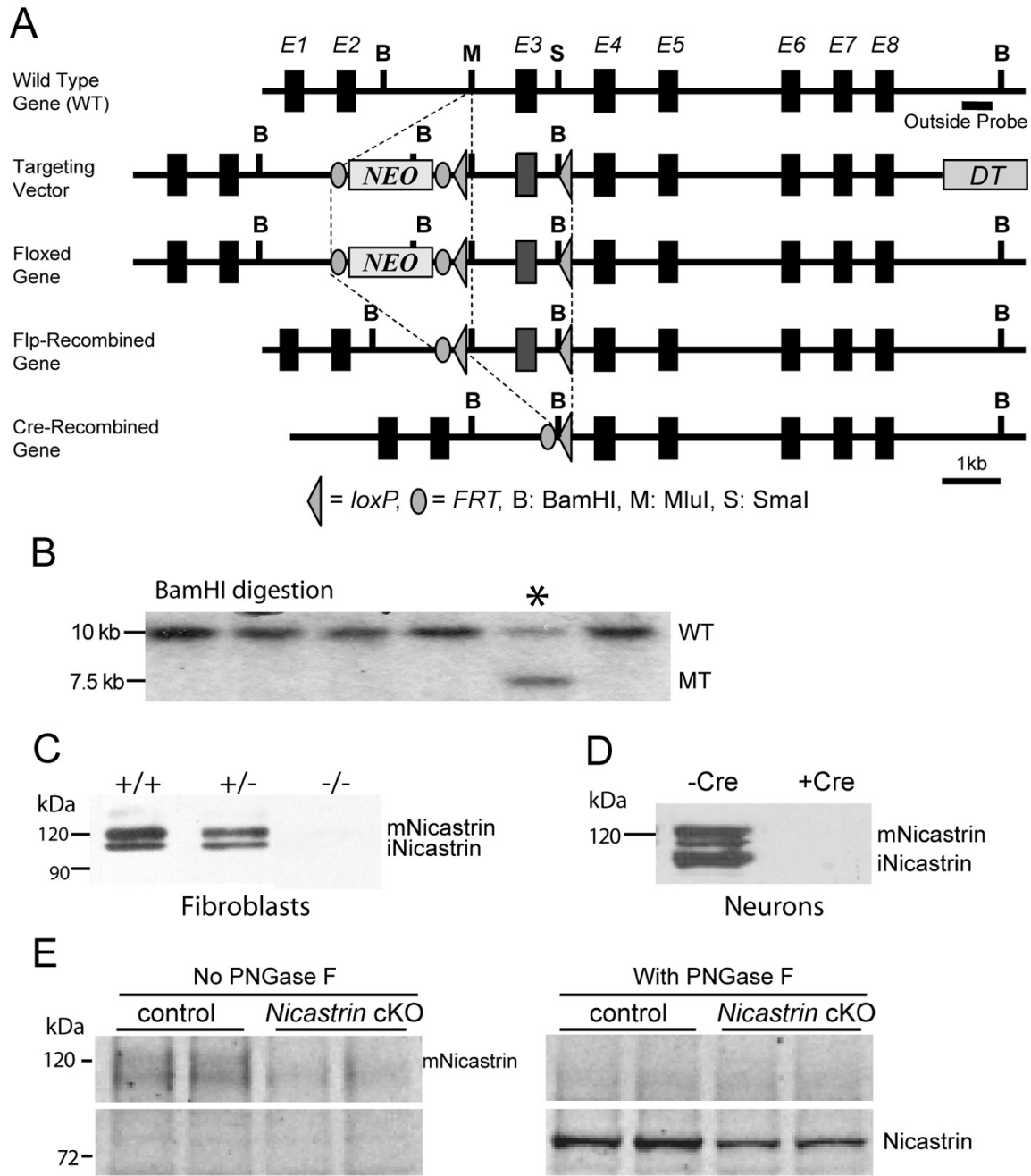

With PNGase F

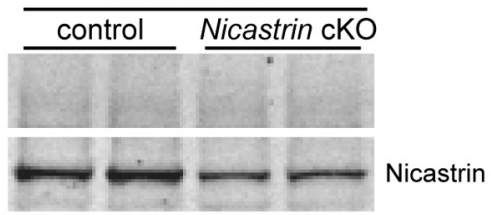

Nicastrin cKO mice

Figure 1. Generation of nicastrin cKO mice. $A$, Targeting strategy. Exon 3 of the nicastrin gene was flanked by two loxP sites (gray arrowheads) and a NEO selection cassette with two FRT sites (gray circles). The diagram is not drawn to scale. B, Southern 列 screening for properly recombined ES cells. Genomic DNA extracted from transfected ES cells was digested with BamHI and blotted with a 3' outside probe. The presence of the $7.5 \mathrm{~kb}$ BamHl fragment indicates the occurrence of the proper homologous recombination event in ES cells, which represents the mutant allele and is indicated by the asterisk. WT, Wild-type band; MT, with lentivirus expressing Cre recombinase to establish nicastrin $\mathrm{KO}$ cell line $(-/-)$. No mature or immature nicastrin protein is detected in nicastrin KO fibroblasts. "mNicastrin" denotes mature nicastrin. "iNicastrin" denotes immature nicastrin. $\boldsymbol{D}$, Neuronal s prepared from newborn fnicastrin/fnicastrin mice were infected with either the control (-Cre) or Cre lentiviruses at DIV4 Lysates were collected at DIV14 and immunoblotted for nicastrin. Neither mature nor immature nicastrin protein is detected in nicastrin $\mathrm{KO}$ cultured neurons, indicating that introduction of Cre eliminates nicastrin expression. $\boldsymbol{E}$, Immunoblotting of nicastrin cosylate nicastrin. Levels of deglycosylated nicastrin protein are reduced at $\sim 50 \%$ in the nicastrin cKO cortex. The asterisk denotes statistical significance $\left({ }^{*} p<0.05\right)$.

which encodes neomycine resistance (NEO) and is flanked by two FRT ( flipase recognition target) sites, into intron 2 (Fig. $1 A$ ). The targeting vector was transfected into R1 embryonic stem (ES) cells, and the resulting ES cell clones were screened by Southern analysis using a $3^{\prime}$ external probe (Fig. $1 B$ ). Positive ES cell clones carrying the proper homologous recombination event were further confirmed by PCR, and then injected into mouse blastocysts to generate chimeric mice, which were bred with $\mathrm{C} 57 \mathrm{BL} / 6 \mathrm{~J}$ mice. To remove the NEO selection cassette, we crossed $\mathrm{F}_{1}$ heterozygous mice with $f l p$ deleter mice (Dymecki, 1996) and generated floxed nicastrin mice. We also crossed floxed nicastrin mice to protamine-Cre transgenic ( $\mathrm{Tg}$ ) mice, in which Cre recombinase is 
A
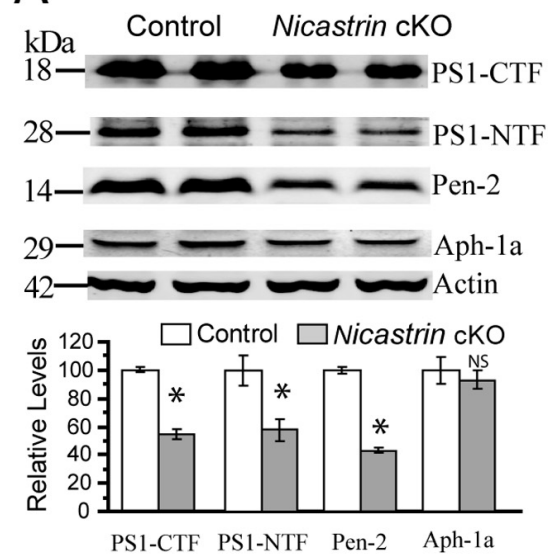

C
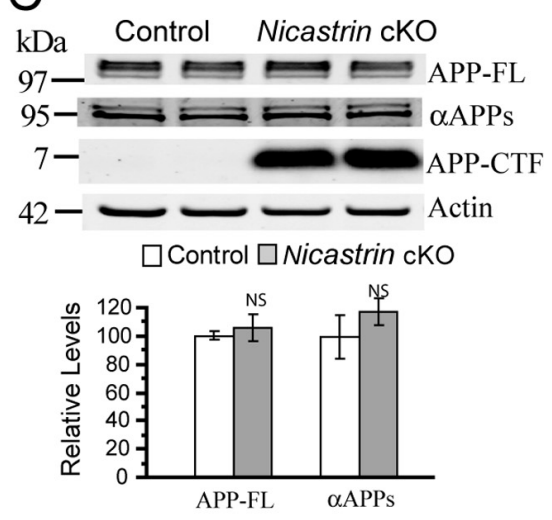

$E$

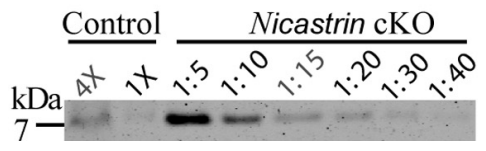

B
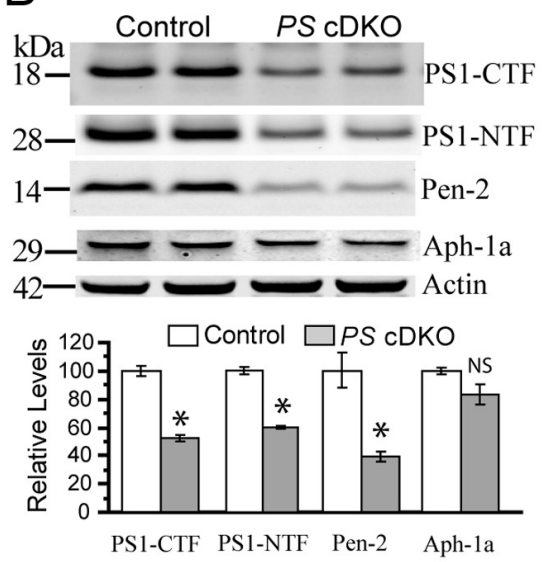

$\mathrm{D}$
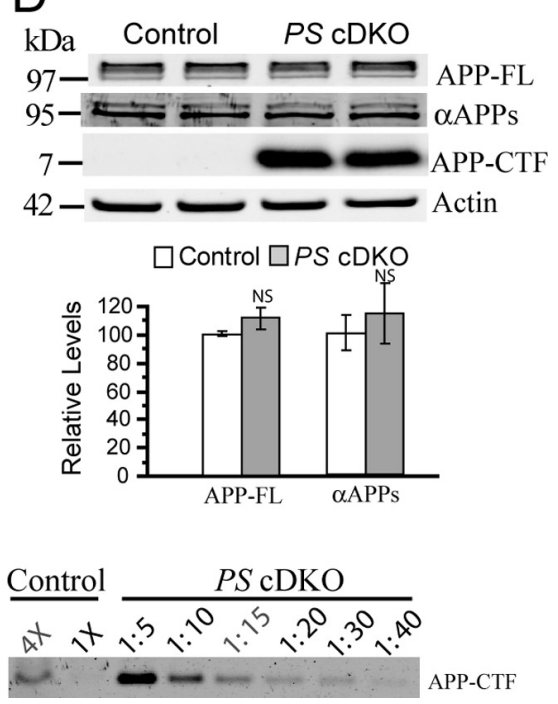

Figure 2. Levels of $\gamma$-secretase subunits and APP cleaved products in nicastrin cKO and PS CDKO mice at 2 months of age. $\boldsymbol{A}$, Significant reductions of the levels of PS1-CTF, PS1-NTF, and Pen-2 but unchanged levels of Aph-1a in nicastrin cK0 mice. Cortical lysates from nicastrin cK0 and control mice were analyzed by immunoblotting (top) using antibodies against PS1-CTF, PS1-NTF, Pen-2, and Aph-1a. Protein levels were standardized with $\beta$-actin (bottom). The asterisk denotes statistical significance $\left({ }^{*} p<\right.$ 0.05). NS denotes not significant. $\boldsymbol{B}$, Reductions of $\gamma$-secretase subunits in PS CDKO mice. Conditional removal of PSs results in a $\sim 50 \%$ reduction of PS1-CTF and PS1-NTF levels, which is similar to the observation in nicastrin cK0. Reduced levels of Pen-2 but unchanged levels of Aph-1a are observed in PS CDKO mice. Cortical lysates from PS CDKO and control mice were analyzed by immunoblotting (top). Protein levels were standardized with $\beta$-actin (bottom). The asterisk denotes statistical significance $\left({ }^{*} p<0.05\right)$. C, D, Unchanged levels of APP full-length (APP-FL) and soluble APP- $\alpha$ fragment $(\alpha \mathrm{APP}$ ) in nicastrin $\mathrm{KK}(\boldsymbol{C})$ and PS CDKO mice (D). Immunoblotting (top) was conducted using antibodies specific for APP-FL and $\alpha$ APPs. Protein levels were standardized with $\beta$-actin (bottom). Quantification analysis shows no significant changes in protein levels for APP-FL and $\alpha$ APPs but a massive increase in protein levels for APP-CTFs in nicastrin CKO and PS CDKO mice, relative to those in control mice. E, Direct comparison of immunoblotting on APP-CTFs in nicastrin CKO and PS CDKO mice at 2 months of age. Cortical lysates prepared from nicastrin $\mathrm{CKO}$ and PS CDKO mice were diluted as indicated (lanes 3-8) and immunoblotted with the APP (8 antibody. Undiluted homogenate $(1 \times)$ and four times of the undiluted homogenate $(4 \times)$ from control mice were also immunoblotted. The levels of APP-CTFs in nicastrin cKO and PS CDKO cortex were increased $\sim 60$-fold relative to those of the control mice.

expressed in male germ cells, to generate germline nicastrin $\mathrm{KO}$ (nicastrin $^{-1-}$ ) mice.

Since nicastrin ${ }^{-1-}$ mice exhibited early embryonic lethality, we examined levels of nicastrin protein in nicastrin $^{-1-}$ fibroblasts. Fibroblasts derived from embryos carrying nicastrin floxed and deleted alleles (fnicastrin/-) at day 13.5 were immortalized and infected with the lentivirus expressing Cre recombinase to establish nicastrin ${ }^{-1-}$ cells. No nicastrin protein was detected in nicastrin $^{-1-}$ cells (Fig. 1C), whereas $\sim 50 \%$ nicastrin protein was observed in nicastrin ${ }^{+/-}$cells, compared with wild-type cells. Moreover, when we infected cultured primary cortical neurons derived from newborn fnicastrin/fnicastrin mice with a lentivirus expressing Cre recombinase, nicastrin levels were undetectable in these neurons (Fig. 1D), confirming that the presence of Cre eliminates nicastrin expression.

Postnatal forebrain-specific nicastrin cKO mice were generated by crossing f $n i$ castrin/fnicastrin mice to transgenic mice that express Cre recombinase specifically in excitatory neurons of postnatal forebrain under the control of the $\alpha$ CaMKII promoter (Yu et al., 2001). To determine the level of nicastrin in the cortex of nicastrin cKO mice, we prepared cortical lysates at 2 months of age and performed Western analysis (Fig. $1 E$ ). Since nicastrin is modified by posttranslational glycosylation, we also treated the cortical lysates with peptide- $N$-glycosidase F (PNGase F) to remove saccharide groups from the mature glycosylated form of nicastrin proteins, and then performed Western analysis. We found a reduction of $\sim 50 \%$ in the levels of the deglycosylated form of nicastrin in nicastrin $\mathrm{cKO}$ mice at this age (Fig. $1 E$ ). The residual amount of nicastrin in these mice may be attributable to the expression of nicastrin in glia, interneurons, and a small percentage of excitatory neurons that lack Cre expression.

\section{Reduced levels of $\gamma$-secretase components and impaired APP processing in nicastrin cKO mice} To determine the effects of nicastrin inactivation on other components of the $\gamma$-secretase complex, we measured the levels of PS1, Pen-2, and Aph-1a in cortical lysates of 2-month-old nicastrin cKO mice. We found a $50 \%$ of reduction in the C-terminal (PS1-CTF) and N-terminal fragments of PS1 (PS1-NTF), suggesting that inactivation of nicastrin significantly affects protein levels of PS1 (Fig. 2A). We observed a $\sim 60 \%$ reduction in Pen-2 levels (Fig. 2A). In contrast, levels of Aph-1a were unchanged in nicastrin cKO mice (Fig. 2A). These results suggest that inactivation of nicastrin significantly affects protein levels of other components of the $\gamma$-secretase complex, consistent with previous findings (Steiner et al., 2002; Gu et al., 2003). In parallel, we also measured the levels of PS1-CTF, PS1-NTF, Pen-2, and Aph-1a in cortical lysates of 2-month-old PS cDKO mice. We found comparable reductions on PS1-CTF, PS1-NTF, and Pen-2 levels, but no significant change on Aph-1a levels (Fig. 2 B).

Next, we examined whether loss of nicastrin alters APP processing in the adult cerebral cortex. Western analysis revealed normal levels of APP full-length (APP-FL) protein in nicastrin cKO mice (Fig. 2C), indicating that nicastrin inactivation does not alter the expression of APP. Levels of soluble APP $\alpha$ ( $\alpha$ APPs) were also normal in the cortex of nicastrin cKO mice (Fig. 2C). 
APP C-terminal fragments (APP-CTFs), however, accumulated in the cortex of nicastrin cKO mice (Fig. 2C). Similarly, Western analysis of cortical lysates of $P S$ cDKO mice at 2 months indicated that levels of APP-FL and $\alpha$ APPs were not changed (Fig. 2 D), but levels of APP-CTFs were significantly increased (Fig. 2D).

To quantify the extent of increases in APP-CTFs, we performed Western analysis using a serial dilution of nicastrin $\mathrm{cKO}$ cortical lysates at 2 months of age (Fig. $2 E)$. We found that APP-CTFs levels in nicastrin $\mathrm{cKO}$ mice were increased $\sim 60$ fold, relative to those in the control. Furthermore, we similarly compared levels of APP-CTFs in nicastrin cKO mice with those in $P S$ cDKO mice at the same age and found that levels of APP-CTFs were also increased $\sim 60$-fold in $P S$ cDKO mice (Fig. $2 E)$. These results indicate that, like PS, nicastrin is essential for $\gamma$-secretasemediated processing of APP.

\section{Normal brain morphology in nicastrin cKO mice at 2 months}

Although nicastrin ${ }^{-1-}$ mice exhibit embryonic lethality (Li et al., 2003a,b), nicastrin cKO mice were viable and visually indistinguishable from their littermate controls during early adulthood. To address whether inactivation of nicastrin affects brain morphology, we performed Nissl staining using brain sections from nicastrin cKO mice at 2 months of age. Nisslstained histology revealed grossly normal brain architecture in cKO mice (Fig. 3A). Unbiased stereological counting of neurons in the $\mathrm{cKO}$ cortex uncovered no significant changes in total cortical neuronal number $(F=1.3$; $\mathrm{df}=1,4 ; p>0.3)$, or in cortical $(F<1)$ and hippocampal volumes $(F<1)$ (data not shown). Immunohistological analysis revealed no significant changes in immunoreactivities of MAP2 and synaptophysin (SVP38) in the neocortex and the hippocampus, suggesting normal dendrites and synapses in nicastrin cKO mice (Fig. $3 B, C$ ). These results indicate no detectable changes in brain morphology and total cortical neuronal number in nicastrin cKO mice at 2 months.

\section{Progressive impairment of spatial learning and memory in nicastrin cKO mice}

To test whether loss of nicastrin affects learning and memory, we examined hippocampus-dependent spatial learning in nicastrin cKO and littermate control mice at 2-3 and at 7-8 months of age, using the Morris water maze (MWM) task (Morris et al., 1982). We trained the mice to learn the location of a hidden platform in the MWM for $7 \mathrm{~d}$ [for acquisition curves, see Fig. $4 A(2-3$ months), $B$ (7-8 months)]. First, we performed an ANOVA to evaluate overall effects for all mice. The ANOVA revealed a highly significant within-subject effect during training $(F=42.9$; $\mathrm{df}=$ 4.6, 210.7; $p<0.0000001)$ as expected. The overall ANOVA also revealed a highly significant main genotype effect $(F=27.9$; $\mathrm{df}=$ 1,$46 ; p<0.00001$ ), suggesting impaired spatial learning in nicastrin $\mathrm{cKO}$ mice. We further compared the behavioral performance for each age separately, and confirmed a significant genotype effect (2-3 months; $F=5.4$; $\mathrm{df}=1,22 ; p<0.05 ; 7-8$ months;
$F=32.0 ; \mathrm{df}=1,24 ; p<0.00001)$. Furthermore, the overall ANOVA showed a highly significant age effect in nicastrin mutant mice $(F=28.2$; df $=1,23$; $p<0.00001)$ but only a "trend" in control mice $(F=3.54 ; \mathrm{df}=1,23 ; p=0.07)$. Overall, these results indicate that nicastrin $\mathrm{cKO}$ mice exhibit a progressive impairment in spatial learning.

After the MWM training, the mice were subjected to a probe test, in which the hidden platform was removed from the water maze and the mice were allowed to swim freely in search for the former platform location in the target quadrant (Fig. 4C, 2-3 months; $D, 7-8$ months). First, we conducted an overall ANOVA to compare the time spent in the target quadrant and the other three quadrants by all mice. We found a significant quadrant effect $(F=6.0$; df $=1,30 ; p<0.025)$, suggesting a searching preference to the target quadrant after the training. Second, we performed an overall ANOVA to compare the time spent in the target quadrant, and found a significant genotype effect $(F=$ $10.9 ; \mathrm{df}=1,30 ; p<0.005)$, consistent with impaired spatial memory in nicastrin $\mathrm{cKO}$ mice. We then conducted data analysis for 2-3 and 7-8 months separately. We found a significant genotype effect on the time spent in the target quadrant for 2-3 months $(F=8.8$; df $=1,22 ; p<0.01)$ (Fig. $4 C)$ and a highly significant genotype effect for $7-8$ months $(F=13.2$; df $=1,24$; $p<0.001$ ) (Fig. $4 D$ ). Figure $4, E$ and $F$, show swim paths during the probe trial for 2-3 and 7-8 months groups, respectively. Both younger and older control mice spent much more time in the target quadrant than the age-matched nicastrin $\mathrm{CKO}$ mice, providing additional evidence for a progressive impairment in spatial memory in nicastrin cKO mice.

To exclude the possibility that the impairment in spatial memory in young nicastrin cKO mice is secondary to abnormal 


\section{2-3 months}

A

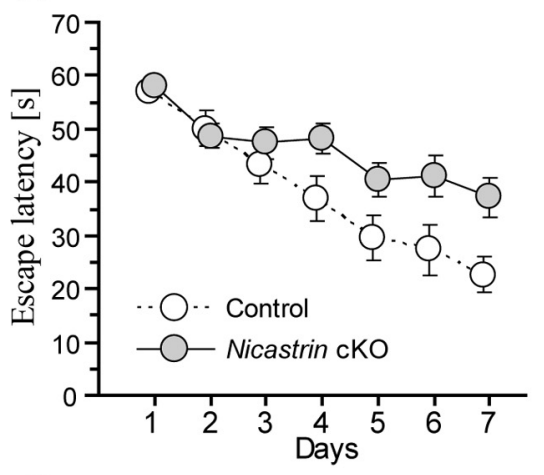

C

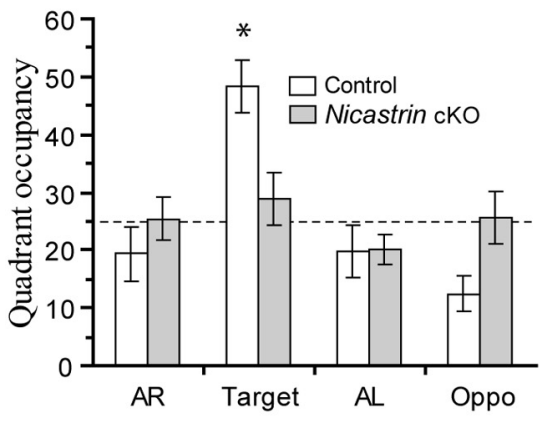

E

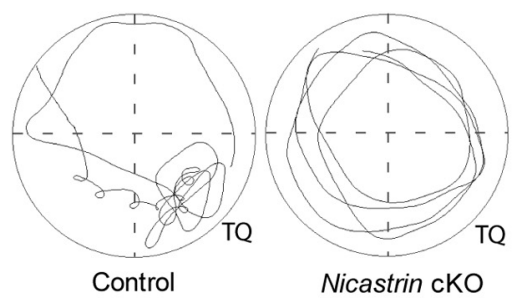

G

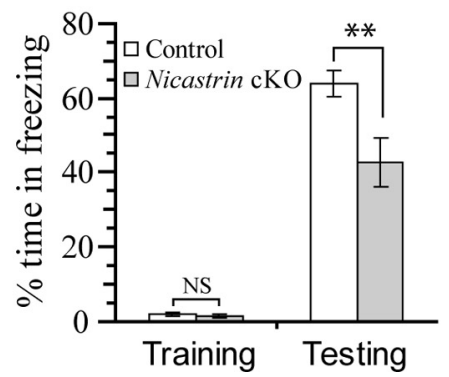

\section{7-8 months}

B

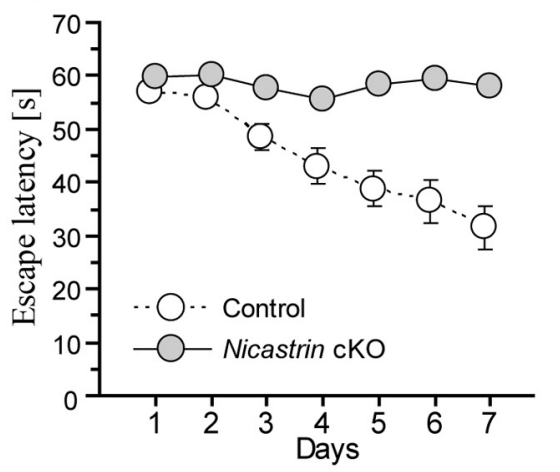

D

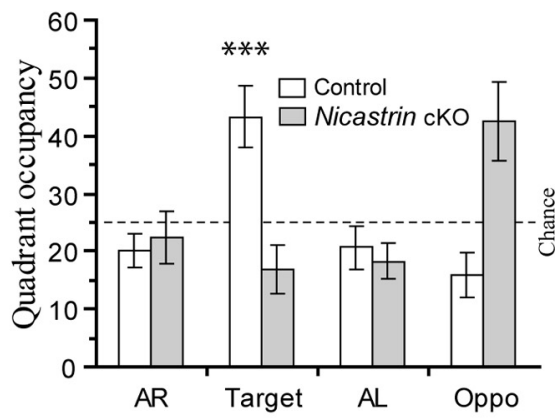

$\mathrm{F}$

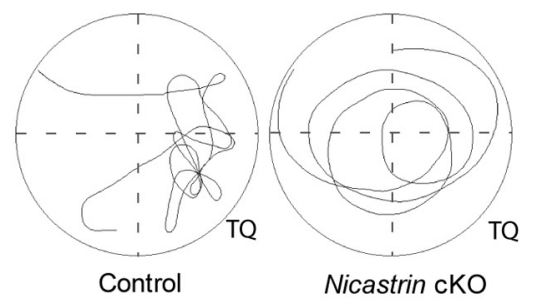

$\mathrm{H}$

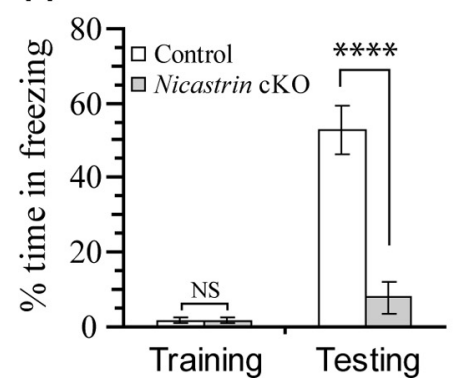

Figure 4. Progressive impairment of learning and memory in nicastrin $\mathrm{CKO}$ mice. nicastrin $\mathrm{KK} 0$ and control mice at two different ages, 2-3 and 7-8 months, were examined in the Morris water maze to test spatial learning and memory, and in the contextual fear conditioning to test associative memory. $\boldsymbol{A}$, Escape latency in nicastrin cKO mice at 2-3 months. nicastrin cKO mice display longer escape latencies than age-matched littermate control animals across the $7 \mathrm{~d}$ training period $(n=10$ for control; $n=14$ for nicastrin (KO). Error bars indicate SEM. B, Escape latency in nicastrin cKO mice at 7-8 months. Almost no improvement in escape latencies was observed in nicastrin cK0 mice across the $7 \mathrm{~d}$ training period ( $n=15$ for control; $n=11$ for nicastrin cK0). C, Probe trial in nicastrin CKO mice at 2-3 months of age. Two- to three-month-old nicastrin cKO mice spend significantly less time searching for the platform in the target quadrant than the controls. The asterisk denotes statistical significance $\left({ }^{*} p<0.05\right)$. AL, Adjacent left quadrant; $T$, target quadrant; $A R$, adjacent right quadrant; $0 P$, opposite quadrant. Twenty-five percent is the chance performance during the probe trial. $D$, Probe trial in nicastrin CKO mice at 7-8 months of age. The time spent in the target quadrant is dramatically decreased in 7-to 8-month-old nicastrin cKO mice compared with the controls $(F=13.2 ; \mathrm{df}=1,24 ; p<$ 0.001). Of note, the time spent in the opposite quadrant in which they were initially released is significantly increased in the $c K 0$ group $(F=12.9 ; \mathrm{df}=1,24 ; p<0.001)$. The asterisks denote statistical significance $\left.{ }^{* * *} p<0.001\right)$. $\boldsymbol{E}, \boldsymbol{F}$, Representative swim paths for mice at $2-3(\boldsymbol{E})$ and $7-8(\boldsymbol{F})$ months of age during the posttraining probe trial. TQ, Target quadrant. $\boldsymbol{G}$, Percentage of

sensorimotor functions, we analyzed thigmotaxis during the hidden-platform training. We found no significant genotype effect on the time spent swimming 10 $\mathrm{cm}$ within the walls of the water maze (supplemental Fig. 1A, available at www. jneurosci.org as supplemental material), suggesting no abnormal anxiety levels in nicastrin $\mathrm{CKO}$ mice. We then performed a visible cued task to examine sensorimotor functions (supplemental Fig. $1 B$, available at www.jneurosci.org as supplemental material) and again found no significant genotype effect on the latency to find the visible platform. We examined open field activity and motor coordination using a cohort of naive mice at 2 months. We found no significant differences between the control and the $\mathrm{cKO}$ mice in horizontal activity, vertical activity, and total distance traveled in the open field (supplemental Fig. $2 A-C$, available at www.jneurosci.org as supplemental material). We found no significant genotype difference in latency to fall from the rotarod as well (supplemental Fig. $2 D$, available at www.jneurosci.org as supplemental material). These data suggest that impairment on spatial learning and memory is unlikely caused by abnormal sensorimotor functions.

\section{Progressive impairment of contextual} fear memory in nicastrin cKO mice

To investigate the effect of the loss of nicastrin on associative memory, we conducted a contextual fear conditioning task, in which robust hippocampus-dependent associative memory can be acquired in a single trial (Phillips and LeDoux, 1992). In this task, mice learn to associate a conditioned stimulus (test chamber) with an unconditioned stimulus (footshock). After pairing of the conditioned and unconditioned stimulus, the formation of an associative memory causes the presentation of the conditioned stimulus alone to elicit a fear response (e.g., freezing).

\section{$\leftarrow$}

time spent in freezing in nicastrin cKO mice at 2-3 months of age in the contextual fear conditioning. Nicastrin cKO mice spend significantly less time freezing than age-matched littermate control animals $24 \mathrm{~h}$ after the footshock ( $p<0.01$; $n=28$ for control; $n=25$ for nicastrin (K0); however, they show indistinguishable levels of freezing to control mice during the training period. The asterisks denote statistical significance $\left.{ }^{* *} p<0.01\right)$. NS denotes not significant. $\boldsymbol{H}$, Percentage of time in freezing in nicastrin cKO mice at 7-8 months of age in the contextual fear conditioning. Nicastrin cK0 mice spend significantly less time in freezing than the controls $24 \mathrm{~h}$ after the footshock $(p<0.00001 ; n=13$ for control; $n=10$ for Nicastrin (K0), but they exhibit comparable levels of freezing to control mice during the training period. The asterisks denote statistical significance $\left({ }^{* * * *} p<0.001\right)$. 
We examined 2-3 and 7-8 months old nicastrin $\mathrm{cKO}$ and littermate control mice (Fig. 4G,H). An overall ANOVA was performed for all mice. First, the ANOVA revealed a highly significant within-subject effect $(F=169.2 ; \mathrm{df}=1,72 ; p<0.00001)$ on intervals (training vs $24 \mathrm{~h}$ postshock), suggestive of effective associative memory. Second, the ANOVA also revealed a highly significant main genotype effect $(F=30.1$; $\mathrm{df}=1,72 ; p<0.00001)$ and a highly significant interval by genotype interaction $(F=32.3 ; \mathrm{df}=1,72 ; p<0.001)$, suggesting impaired long-term associative fear memory in nicastrin cKO mice. Third, the ANOVA indicated a significant age effect $(F=13.2 ; \mathrm{df}=1,72 ; p<0.001)$, suggesting that the performance of older mice was worse than that of younger ones. We then performed data analysis for each age. At 2-3 months (Fig. 4G), nicastrin cKO mice displayed significantly less freezing $24 \mathrm{~h}$ after the footshock (control, $63.8 \pm 3.6 \%$; $\mathrm{cKO}, 42.7 \pm 6.6 \% ; F=8.3 ; \mathrm{df}=1,51 ; p<$ $0.006)$, but exhibited normal exploratory activity in the freezing chamber during the training period (control, $1.9 \pm 0.5 \%$; $\mathrm{CKO}$, $1.4 \pm 0.5 \% ; F<1)$, suggesting impaired associative memory. At 7-8 months (Fig. $4 \mathrm{H})$, nicastrin $\mathrm{cKO}$ mice again displayed significantly less freezing $24 \mathrm{~h}$ after the footshock (control, $52.7 \pm 6.6 \%$; cKO, $7.8 \pm 4.1 \% ; F=33.8 ; \mathrm{df}=1,21 ; p<$ $0.000001)$, whereas they showed normal exploratory activity during the training period (control, $1.6 \pm$ $0.9 \%$; cKO, $1.7 \pm 0.7 \% ; F<1$ ), indicating an even more severely impaired associative memory than at $2-3$ months of age.

Interestingly, the overall ANOVA further revealed a significant interval by genotype by age interaction $(F=5.4 ; \mathrm{df}=1,72$; $p<0.025$ ), suggesting that there is a progressive decline of fear associative memory in nicastrin cKO mice. We performed an ANOVA for the two control groups and found a highly significant within-subject effect on interval $(F=266.0$; $\mathrm{df}=1,39 ; p<$ $0.0001)$ but no significant age effect $(F=1.6 ; \mathrm{df}=1,39 ; p>0.2)$. We also performed an ANOVA for the two cKO groups, and found a highly significant within-subject effect on interval $(F=$ $18.4 ; \mathrm{df}=1,33 ; p<0.0005)$ and a highly significant age effect $(F=11.9 ; \mathrm{df}=1,33 ; p<0.002)$. Therefore, these data suggest a progressive decline of fear associative memory in nicastrin $\mathrm{cKO}$ mice.

\section{Age-dependent cortical neuronal loss in nicastrin cKO mice}

The age-related deterioration of memory in nicastrin $\mathrm{cKO}$ mice prompted us to examine whether loss of nicastrin in the adult cerebral cortex causes age-dependent anatomical alterations. We counted the total number of cortical neurons and measured the total cortical volume in nicastrin $\mathrm{CKO}$ mice at 6 and 9 months of age $(n=4$ per genotype) using stereological method. Whereas the size of the cortex was normal in nicastrin cKO mice at 2 months (Fig. 3), we observed massive cortical atrophy at 6 and 9 months in nicastrin cKO mice (Fig. 5A). Our stereological quantification results showed that, compared with age-matched controls, the total cortical neuron number in the $\mathrm{cKO}$ group was significantly decreased at 6 (data not shown) and 9 months (data not shown). We performed an overall ANOVA on the total cortical neuron number for all three ages. The ANOVA revealed a highly significant main genotype effect $(F=54.6$; $\mathrm{df}=1,16 ; p<$ $0.0001)$ and a highly significant genotype by age interaction effect $(F=10.6 ; \mathrm{df}=2,16 ; p<0.005)$, strongly suggesting a significant age-dependent neuronal loss in the cortex of nicastrin cKO mice. Our stereological results showed that the neocortical volume in cKO mice was significantly decreased at 6 (data not shown) and 9 months (data not shown). An overall ANOVA indicated a highly significant main genotype effect on cortical volume $(F=206.4$; $\mathrm{df}=1,16 ; p<0.0001)$ and a highly significant genotype by age interaction effect $(F=45.8 ; \mathrm{df}=2,16 ; p<0.0001)$, suggesting a striking age-dependent cortical atrophy in nicastrin cKO mice. Together, these results show that loss of nicastrin in the forebrain causes age-dependent cortical neuronal loss in mice.

We further performed immunohistological staining for MAP2 and synaptophysin using brain sections of nicastrin $\mathrm{CKO}$ mice at 6 and 9 months (Fig. $5 B-E$ ). We observed a significant reduction in MAP2 immunoreactivity in the neocortex and the hippocampus of nicastrin cKO mice at these two ages (Fig. $5 B, C$ ). To quantify these changes, we performed Western analysis using cortical lysates from nicastrin cKO mice at 2 and 6 months of age using MAP2 antibodies (supplemental Fig. $3 A$, available at www.jneurosci.org as supplemental material). We found that MAP2 levels in nicastrin cKO mice kept unchanged at 2 months, but were reduced at 6 months. Our immunohistological data also revealed a progressive reduction on synaptophysin immunoreactivity in the neocortex and the hippocampus of nicastrin $\mathrm{CKO}$ 
A

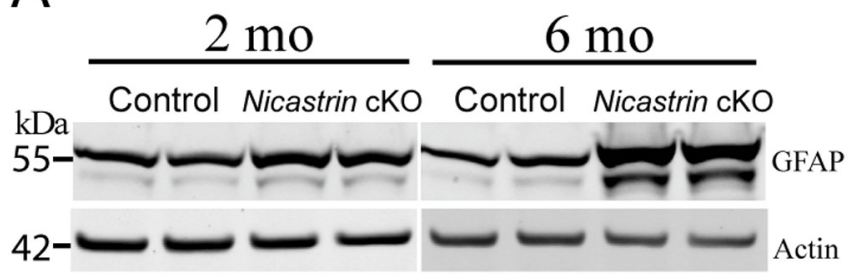

B

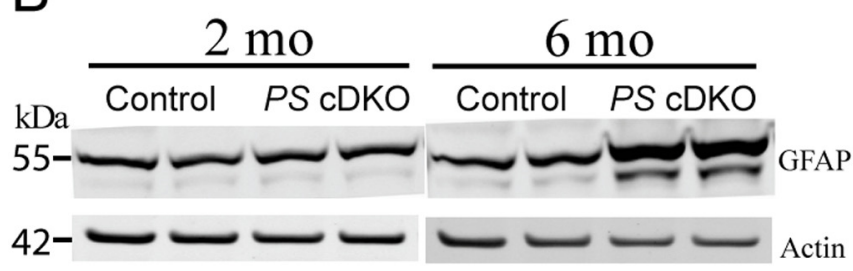

C

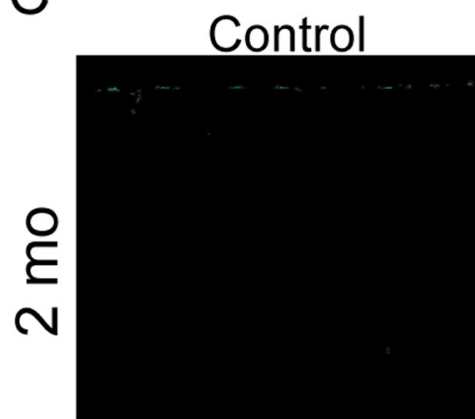

Nicastrin cKO
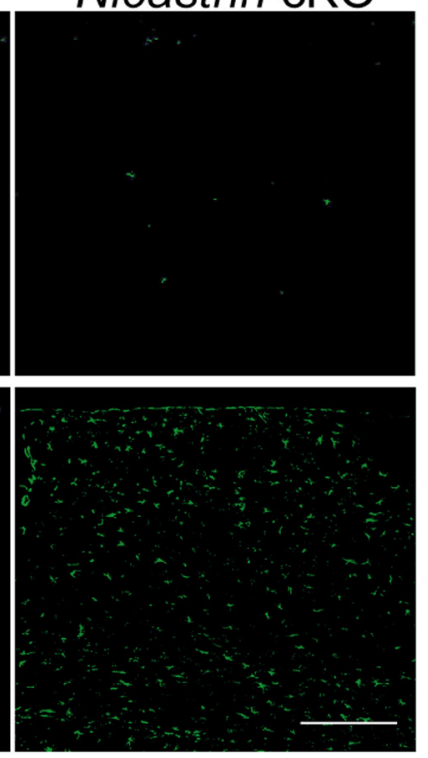

D

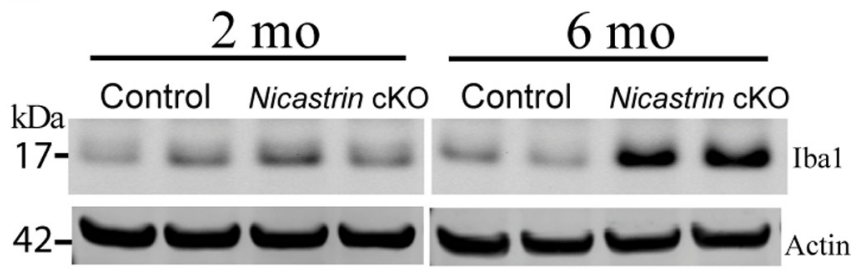

E
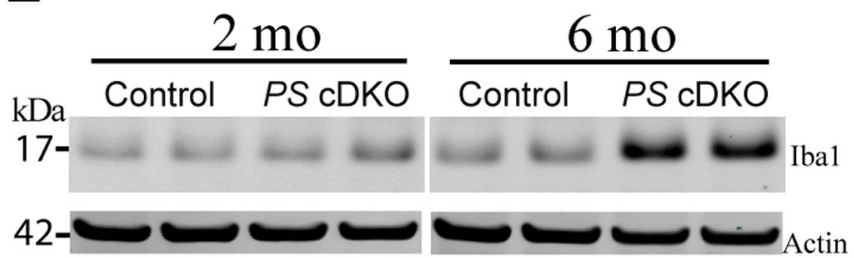

F
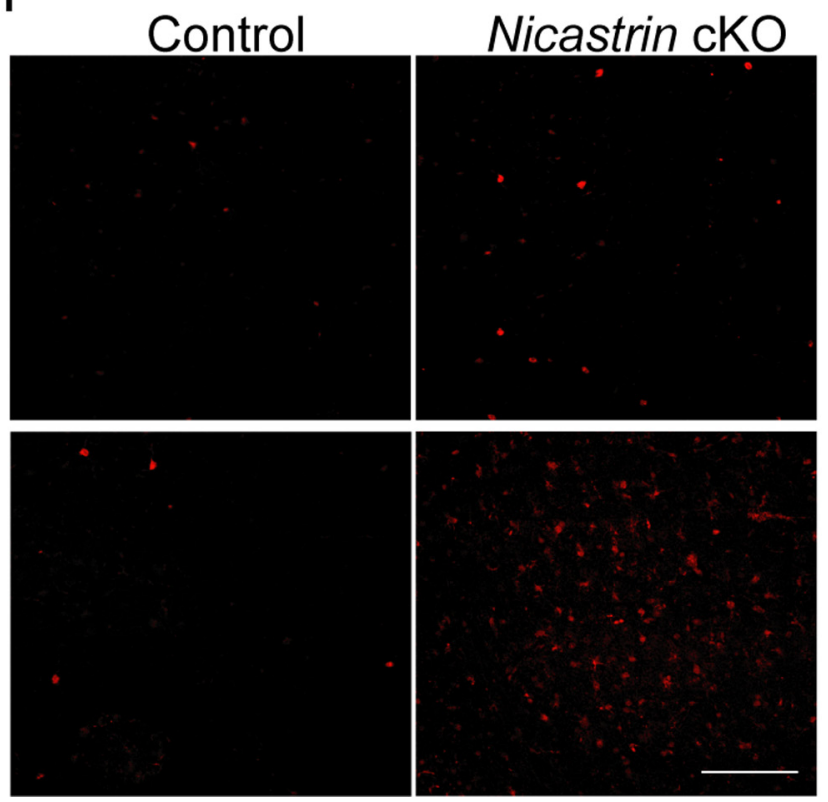

Figure 6. Progressive gliosis in nicastrin $\mathrm{CKO}$ and PS CDKO mice. A, Western analysis on protein levels of GFAP, a marker for astrocytes. There is a progressive increase of GFAP levels in cortical lysates of nicastrin cKO mice. At 2 months, GFAP levels are higher in nicastrin cKO mice $(p<0.05)$. However, at 6 months, there is an $\sim 3$-fold increase in GFAP levels in the cortex of nicastrin cK0 mice. $B$, Age-related increase of GFAP levels in PS CDKO mice. There is a small increase on GFAP levels between the control and PS CDKO mice at 2 months. At 6 months, there is a twofold increase in GFAP levels in PS CDKO mice. C, Immunostaining of GFAP in the neocortex of nicastrin $\mathrm{CKO}$ mice. There is a progressive astrocytosis in nicastrin cKO mice. In nicastrin cKO mice, there is a small increase in GFAP immunoreactivity at 2 months and a dramatic increase at 6 months. Scale bar, $200 \mu \mathrm{m}$. D. Western analysis on protein levels of Iba 1, a marker for microglia. There is a progressive increase of Iba1 levels in cortical lysates of nicastrin cK0 mice. At 2 months, Iba1 levels are higher in nicastrin cK0 mice. At 6 months, there is a sixfold increase in lba1 protein levels. $E$, Age-related increase of Iba 1 levels in PS CDKO mice. There is a small increase in Iba1 levels in PS CDKO mice at 2 months and a threefold increase in Iba1 levels at 6 months. $F$, Immunostaining of Iba1 in the neocortex of nicastrin cKO mice. There is a progressive microgliosis in nicastrin cKO mice. Iba1 immunoreactivity is increased in the cKO cortex at 2 months and highly elevated at 6 months. Scale bar, $100 \mu \mathrm{m}$.

mice at 6 (Fig. 5D) and 9 (Fig. 5E) months. Our Western analysis in synaptophysin using cortical lysates at 2 and 6 months confirmed an age-related reduction (supplemental Fig. $3 B$, available at www.jneurosci.org as supplemental material). These results indicate age-dependent loss of dendrites and synapses in aging nicastrin $\mathrm{CKO}$ mice.

Progressive gliosis in nicastrin cKO mice

Since neurodegeneration is often accompanied by inflammatory responses, we assessed the levels of inflammatory markers in nicastrin $\mathrm{cKO}$ mice. To examine whether there is ongoing, progressive astrogliosis in the nicastrin cKO cortex, we performed Western analysis on GFAP, a marker for reactive astrocytes, using cortical lysates at 2 and 6 months. We found that there was a small but significant increase in GFAP levels in nicastrin cKO mice at 2 months (Fig. 6A) $(133 \pm 8.0 \%$ of nicastrin cKO vs $100 \pm 9.1 \%$ of control; $p<0.025$ ) and a robust increase at 6 months (Fig. $6 A$ ) $(399 \pm 20.0 \%$ of nicastrin cKO vs $100 \pm 23.3 \%$ of control; $p<$ $0.005)$. In parallel, we conducted Western analysis on GFAP using cortical lysates of $P S \mathrm{cDKO}$ mice at 2 and 6 months, and also observed an age-dependent increase in GFAP levels (Fig. 6B). We then conducted GFAP immunostaining using brain sections of nicastrin cKO mice at 2, 6, and 9 months. GFAP immunoreactivity showed a small increase in the neocortex (Fig. 6C) but no change in the hippocampus (supplemental Fig. $4 A$, available at www.jneurosci.org as supplemental material) at 2 months; how- 

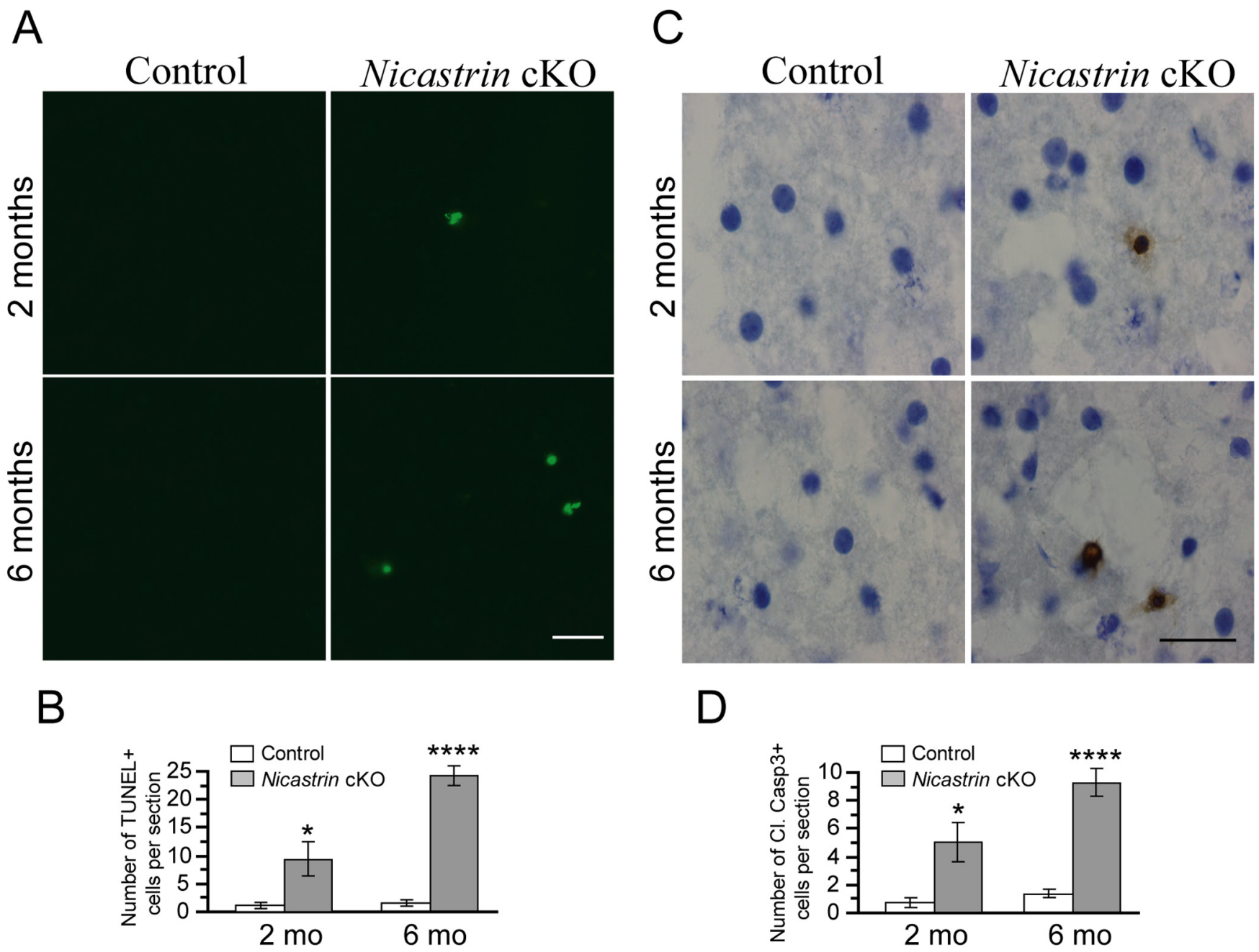

Figure 7. Increased apoptotic cells in nicastrin cKO mice. A, TUNEL staining in the neocortex of nicastrin cKO mice. TUNEL cells are shown in green. At 2 months, TUNEL cells can be seen in the cortex of nicastrin cKO mice. However, many more TUNEL cells can be found in nicastrin cKO mice at 6 months. Control mice do not show TUNEL cells. Scale bar, $25 \mu \mathrm{m}$. B, Quantitative data on the average number of TUNEL cells per section. At 2 months, nicastrin cKO mice show more TUNEL cells in the cortex than control mice (control, $n=4 ;$; $K 0, n=5$ ). At 6 months, there is a highly significant increase on the average number of TUNEL cells in nicastrin cKO mice (control, $n=4 ; \mathrm{CKO}, n=5)$. Error bars indicate SEM. The asterisks denote statistical significance $\left({ }^{*} p<0.05\right.$; $\left.{ }^{* * * *} p<0.001\right)$. C, Active caspase-3 immunostaining in the neocortex of nicastrin cKO mice. The sections were counterstained with hematoxylin. Active caspase-3-positive $(+)$ cells are shown in brown and nonactive caspase-3-positive cells are shown in blue. At 2 months, active caspase-3-positive staining can be seen in nicastrin cK0 mice. At 6 months, nicastrin cK0 mice show many more cells with positive staining for active caspase- 3 in the cortex. Scale bar, $25 \mu \mathrm{m}$. D, Quantification of average numbers of active caspase-3 cells per section. At 2 months, the average number of active caspase-3 is higher in nicastrin cKO than in control mice (control, $n=4 ; \mathrm{KK} 0, n=5$ ). At 6 months, there is a large increase in the average number of active caspase-3 cells in nicastrin cKO mice (control, $n=$ $4 ;(K 0, n=5)$.

ever, GFAP immunoreactivity became progressively elevated in the neocortex (Fig. 6C) and in the hippocampus (supplemental Fig. $4 A$, available at www.jneurosci.org as supplemental material) at 6 and 9 months of age. These data demonstrate a progressive astrocytosis in nicastrin $\mathrm{cKO}$ mice.

In a second set of experiments, we investigated microgliosis in the mutant mice. We conducted Western analysis on ionized calcium-binding adapter molecule 1 (Iba1), which is specifically expressed in microglia in the brain (Imai et al., 1996), using cortical lysates at 2 and 6 months. We observed a significant increase in Ibal levels at 2 months (Fig. 6D) (164 $\pm 23.7 \%$ of nicastrin cKO vs $100 \pm 16.1 \%$ of control; $p<0.05)$ and a very large increase at 6 months (Fig. $6 D)(669 \pm 108.6 \%$ of nicastrin cKO vs $100 \pm 9.2 \%$ of control; $p<0.05)$. We also performed Western analysis on Ibal using cortical lysates of PS cDKO mice at 2 and 6 months and found a progressive increase as well (Fig. 6E). We then conducted Ibal immunohistochemistry. There was a small increase on Ibal immunoreactivity in the neocortex (Fig. $6 F$ ) and the hippocampus (supplemental Fig. $4 B$, available at www. jneurosci.org as supplemental material) at 2 months. In contrast, 6-month-old nicastrin cKO mice showed robust increased Iba1 immunoreactivity in the neocortex (Fig. $6 F$ ) and the hippocampus (supplemental Fig. $4 B$, available at www.jneurosci.org as supplemental material), consistent with progressive microgliosis.

\section{Increased apoptotic cells in nicastrin cKO mice}

To determine whether neurons in nicastrin $\mathrm{cKO}$ mice die via apoptosis, we performed the TUNEL assay using mice at 2 and 6 months of age. We observed a significant increase in the number of TUNEL-positive (TUNEL +) cells in the neocortex of nicastrin cKO mice at 2 months, compared with the control (Fig. $7 A, B$ ) (number of TUNEL + cells per section: nicastrin $\mathrm{cKO}, 9.3 \pm 3$; control, $1.1 \pm 0.4 ; p<0.05 ; n=4-5$ per group), although the apoptotic cells represent a very small percentage of all cortical neurons $(\sim 0.05 \%)$. Similarly, many more TUNEL+ cells were found in the cortex of nicastrin cKO mice at 6 months (Fig. 7) 
(nicastrin cKO, $24.1 \pm 1.8$, vs control, $1.5 \pm 0.4 ; p<0.00001 ; n=$ $4-5$ per group). We also found a significant change in the number of cells that are positive for active caspase- 3 immunostaining in the neocortex of nicastrin cKO mice at 2 months (Fig. 7C,D) (number of active caspase- 3 positive cells per section: $\mathrm{cKO}, 5.0 \pm$ 1.4; control, $0.7 \pm 0.3 ; p<0.05 ; n=4-5$ per group). Furthermore, at 6 months of age, we observed many more cells that are positive for active caspase- 3 in the cortex of nicastrin $\mathrm{cKO}$ mice (cKO, $9.1 \pm 1.0$, vs control, $1.3 \pm 0.3 ; p<0.0005 ; n=4-5$ per group). These results demonstrate an ongoing and progressive apoptosis in nicastrin cKO mice.

\section{Discussion}

Presenilin is a key subunit of the $\gamma$-secretase complex, which is responsible for the cleavage of APP, Notch, and other substrates, and performs essential functions during development and intercellular signaling (Selkoe and Kopan, 2003). Recent studies suggested that in mature, fully developed animals, presenilins are additionally required for neuronal survival and memory formation (Yu et al., 2001; Feng et al., 2004; Saura et al., 2004), although the mechanism remained unclear. In addition to functioning as a $\gamma$-secretase subunit, presenilin possesses $\gamma$-secretase independent activities, such as the regulation of $\mathrm{Ca}^{2+}$ release from the endoplasmic reticulum (De Strooper et al., 1998, 1999; Kang et al., 1999, 2002; Ni et al., 2001; Kim et al., 2002, 2005; LaFerla, 2002; Lammich et al., 2002; Lee et al., 2002; Marambaud et al., 2002; Murakami et al., 2003; Tu et al., 2006). Thus, the question arose whether presenilins support neuronal survival and memory formation by a $\gamma$-secretase-dependent or $\gamma$-secretaseindependent mechanism. Indeed, studies testing the effects of pathogenic presenilin mutants on $\mathrm{Ca}^{2+}$ release from the endoplasmic reticulum suggested that the pathogenic mutations represent a partial loss of this particular function, in a $\gamma$-secretaseindependent manner, and further suggested that this $\gamma$-secretaseindependent activity of presenilin may be responsible for neurodegeneration in Alzheimer's disease (Nelson et al., 2007; Bezprozvanny and Mattson, 2008).

To address this central question, we focused on nicastrin, which like presenilins serves as an essential component of the $\gamma$-secretase complex (Yu et al., 2000; De Strooper, 2003). We investigated the effects of the deletion of nicastrin on neuronal survival and memory formation. Similar to PS germline deletion mice (Shen et al., 1997; Donoviel et al., 1999), constitutive nicastrin $\mathrm{KO}$ mice die during embryonic development ( $\mathrm{Li}$ et al., 2003a,b), making it impossible to study the physiological function of nicastrin in the adult brain in such $\mathrm{KO}$ mice. To overcome this problem, we chose the same strategy as we previously used for presenilins (Yu et al., 2001; Saura et al., 2004), and generated conditional nicastrin $\mathrm{KO}$ mice (Fig. 1). Unlike conventional nicastrin $\mathrm{KO}$ mice (Li et al., 2003a,b), nicastrin cKO mice are viable, appear to be indistinguishable from their littermate controls during their first months of life, and exhibit no major developmental changes (data not shown) (Fig. 3). We characterized the nicastrin $\mathrm{CKO}$ mice as a function of age and compared them with $P S \mathrm{cDKO}$ mice. Our results demonstrate that nicastrin $\mathrm{cKO}$ mice exhibit the same striking phenotype as PS cDKO mice, suggesting that $\gamma$-secretase activity is required for the function and survival of mature neurons. Three major observations were made in the current study.

First, nicastrin cKO mice display a series of biochemical changes consistent with its function as a $\gamma$-secretase subunit. The levels of APP-CTFs, major presynaptic $\gamma$-secretase substrates, are increased massively, whereas the levels of APP and soluble $\alpha$ APPs (produced by $\alpha$-secretase cleavage) are unchanged (Fig. 2C), similar to what was previously observed in PS1 cKO and PS cDKO mice (Yu et al., 2001; Saura et al., 2004, 2005). Moreover, the abundance of two other $\gamma$-secretase subunits, PS1, which is physiologically cleaved into $\mathrm{N}$ - and C-terminal fragments, and Pen-2, are decreased on deletion of nicastrin (Fig. 2A). Interestingly, Pen-2 is also decreased in PS cDKO mice (Fig. $2 B$ ), consistent with recent in vitro findings (Edbauer et al., 2002; Hu et al., 2002), indicating that most of the $\gamma$-secretase subunits depend on each other for stability. Although four $\gamma$-secretase subunits can regulate each other, Aph-1 is least sensitive to changes in expression of the others (De Strooper, 2003). Our findings on unchanged protein levels of Aph-1a in both nicastrin $\mathrm{CKO}$ and PS $\mathrm{cDKO}$ mice are consistent with a previous study (Gu et al., 2003).

Second, nicastrin cKO mice exhibit impairment of learning and memory at 2-3 months of age (Fig. 4), when there is no significant loss of synapses or neurons (Fig. 3). The memory impairment was observed using both Morris water maze and fear conditioning paradigms and is as severe as those observed in PS cDKO mice (Saura et al., 2004). The severity of learning and memory impairment increases with age in nicastrin $\mathrm{cKO}$ mice, such that, at 7-8 months, the mutant mice are completely refractory to learning (Fig. 4).

Last, nicastrin cKO mice develop an age-related, progressive neurodegeneration (Figs. 5, 7), which is as severe as that observed in PS cDKO mice (Saura et al., 2004). The neurodegeneration results in a loss of $\sim 37 \%$ of cortical neurons and a $44 \%$ shrinkage of the cortical volume at 9 months (Fig. 5). Compared with control mice, a significant increase in apoptotic neurons is already apparent at 2 months of age in nicastrin cKO mice, and by 6 months of age the increase in apoptotic neurons is dramatic (Fig. 7). However, the small number of apoptotic neurons found in the cerebral cortex of nicastrin cKO mice at 2 months is insufficient to cause a significant reduction in the total cortical neuron number and the cortical volume. In response to the ongoing cell death, astrocytes and microglia initiate inflammatory responses, which are detectable at 2 months of age and also increase dramatically during aging (Fig. 6). A similar severity of gliosis was detected in PS cDKO mice (Beglopoulos et al., 2004; Saura et al., 2004). Moreover, following up on previous evidence suggesting that accumulation of hyperphosphorylated tau plays an important role in neurodegeneration in $\mathrm{AD}$ (Trojanowski and Lee, 2002), we found that hyperphosphorylated tau levels are also increased at 6 months of age (supplemental Fig. 5, available at www. jneurosci.org as supplemental material).

Thus, our results demonstrate that deletion of either of the two $\gamma$-secretase subunits in mature, fully developed neurons leads to very similar phenotypes, composed of a general destabilization of $\gamma$-secretase complex, a progressive learning and memory impairment, and a severe age-dependent and progressive neurodegeneration. Among others, these data strongly suggest that presenilin and nicastrin maintain neuronal survival through a $\gamma$-secretase-dependent mechanism, rather than a $\gamma$-secretaseindependent activity, such as a presenilin-specific role in regulating $\mathrm{Ca}^{2+}$ release from the endoplasmic reticulum. Furthermore, our data-including the increase in tau phosphorylation, and the widespread apoptosis-are consistent with the notion that the neurodegeneration induced by inactivation of $\gamma$-secretase subunits resembles the neurodegeneration observed in $\mathrm{AD}$. This notion reinforces the need to reconsider the use of $\gamma$-secretase inhibitors as potential treatments of $\mathrm{AD}$ and indicates that much additional work is required to evaluate their potential utility.

Although conclusive with regard to a $\gamma$-secretase-dependent 
mechanism of neurodegeneration, our data do not reveal why $\gamma$-secretase inactivation produces neurodegeneration. At least two principal possibilities exist. First, after $\gamma$-secretase inactivation, accumulation of a particular uncleaved $\gamma$-secretase substrate, such as the APP-CTFs, may be neurotoxic, although this was ruled out at least for APP-CTFs (Rutten et al., 2003). Second, inactivation of $\gamma$-secretase may impair an essential cellular signaling pathway, thereby depriving the neurons of a required signal involved in synapse function and survival. Candidates for such a function include APP (Cao and Südhof, 2001), Notch (De Strooper et al., 1999), and cadherins (Marambaud et al., 2002). However, the lack of conditional knock-out mouse for each of these genes makes it difficult to determine which of these or additional $\gamma$-secretase substrates may be responsible for PSdependent memory and neuronal survival. Uncovering the pathway(s) to neurodegeneration in nicastrin $\mathrm{cKO}$ and $P S \mathrm{cDKO}$ mice will be important for developing potential new avenues to treating neurodegeneration and can now be approached with the availability of these mice.

\section{References}

Beglopoulos V, Sun X, Saura CA, Lemere CA, Kim RD, Shen J (2004) Reduced beta-amyloid production and increased inflammatory responses in presenilin conditional knock-out mice. J Biol Chem 279:46907-46914.

Bezprozvanny I, Mattson MP (2008) Neuronal calcium mishandling and the pathogenesis of Alzheimer's disease. Trends Neurosci 31:454-463.

Brown MS, Ye J, Rawson RB, Goldstein JL (2000) Regulated intramembrane proteolysis: a control mechanism conserved from bacteria to humans. Cell 100:391-398.

Cao X, Südhof TC (2001) A transcriptively active complex of APP with Fe65 and histone acetyltransferase Tip60. Science 293:115-120.

Chen F, Yu G, Arawaka S, Nishimura M, Kawarai T, Yu H, Tandon A, Supala A, Song YQ, Rogaeva E, Milman P, Sato C, Yu C, Janus C, Lee J, Song L, Zhang L, Fraser PE, St. George-Hyslop PH (2001) Nicastrin binds to membrane-tethered Notch. Nat Cell Biol 3:751-754.

Chung HM, Struhl G (2001) Nicastrin is required for Presenilin-mediated transmembrane cleavage in Drosophila. Nat Cell Biol 3:1129-1132.

De Strooper B (2003) Aph-1, Pen-2, and Nicastrin with Presenilin generate an active gamma-Secretase complex. Neuron 38:9-12.

De Strooper B, Saftig P, Craessaerts K, Vanderstichele H, Guhde G, Annaert W, Von Figura K, Van Leuven F (1998) Deficiency of presenilin-1 inhibits the normal cleavage of amyloid precursor protein. Nature 391:387-390.

De Strooper B, Annaert W, Cupers P, Saftig P, Craessaerts K, Mumm JS, Schroeter EH, Schrijvers V, Wolfe MS, Ray WJ, Goate A, Kopan R (1999) A presenilin-1-dependent gamma-secretase-like protease mediates release of Notch intracellular domain. Nature 398:518-522.

Donoviel DB, Hadjantonakis AK, Ikeda M, Zheng H, Hyslop PS, Bernstein A (1999) Mice lacking both presenilin genes exhibit early embryonic patterning defects. Genes Dev 13:2801-2810.

Dymecki SM (1996) Flp recombinase promotes site-specific DNA recombination in embryonic stem cells and transgenic mice. Proc Natl Acad Sci U S A 93:6191-6196.

Edbauer D, Winkler E, Haass C, Steiner H (2002) Presenilin and nicastrin regulate each other and determine amyloid beta-peptide production via complex formation. Proc Natl Acad Sci U S A 99:8666-8671.

Feng R, Wang H, Wang J, Shrom D, Zeng X, Tsien JZ (2004) Forebrain degeneration and ventricle enlargement caused by double knockout of Alzheimer's presenilin-1 and presenilin-2. Proc Natl Acad Sci U S A 101:8162-8167.

Fortini ME (2002) Gamma-secretase-mediated proteolysis in cell-surfacereceptor signalling. Nat Rev Mol Cell Biol 3:673-684.

Gu Y, Chen F, Sanjo N, Kawarai T, Hasegawa H, Duthie M, Li W, Ruan X, Luthra A, Mount HT, Tandon A, Fraser PE, St. George-Hyslop P (2003) $\mathrm{APH}-1$ interacts with mature and immature forms of presenilins and nicastrin and may play a role in maturation of presenilin-nicastrin complexes. J Biol Chem 278:7374-7380.

Hardy J, Selkoe DJ (2002) The amyloid hypothesis of Alzheimer's disease: progress and problems on the road to therapeutics. Science 297:353-356.
Ho A, Morishita W, Atasoy D, Liu X, Tabuchi K, Hammer RE, Malenka RC, Südhof TC (2006) Genetic analysis of Mint/X11 proteins: essential presynaptic functions of a neuronal adaptor protein family. J Neurosci 26:13089-13101.

Hu Y, Ye Y, Fortini ME (2002) Nicastrin is required for gamma-secretase cleavage of the Drosophila Notch receptor. Dev Cell 2:69-78.

Imai Y, Ibata I, Ito D, Ohsawa K, Kohsaka S (1996) A novel gene ibal in the major histocompatibility complex class III region encoding an EF hand protein expressed in a monocytic lineage. Biochem Biophys Res Commun 224:855-862.

Kang DE, Soriano S, Frosch MP, Collins T, Naruse S, Sisodia SS, Leibowitz G, Levine F, Koo EH (1999) Presenilin 1 facilitates the constitutive turnover of beta-catenin: differential activity of Alzheimer's disease-linked PS1 mutants in the beta-catenin-signaling pathway. J Neurosci 19:4229-4237.

Kang DE, Soriano S, Xia X, Eberhart CG, De Strooper B, Zheng H, Koo EH (2002) Presenilin couples the paired phosphorylation of beta-catenin independent of axin: implications for beta-catenin activation in tumorigenesis. Cell 110:751-762.

Kim DY, Ingano LA, Kovacs DM (2002) Nectin-1alpha, an immunoglobulin-like receptor involved in the formation of synapses, is a substrate for presenilin/gamma-secretase-like cleavage. J Biol Chem 277:49976-49981.

Kim DY, Ingano LA, Carey BW, Pettingell WH, Kovacs DM (2005) Presenilin/gamma-secretase-mediated cleavage of the voltage-gated sodium channel beta2-subunit regulates cell adhesion and migration. J Biol Chem 280:23251-23261.

LaFerla FM (2002) Calcium dyshomeostasis and intracellular signalling in Alzheimer's disease. Nat Rev Neurosci 3:862-872.

Lammich S, Okochi M, Takeda M, Kaether C, Capell A, Zimmer AK, Edbauer D, Walter J, Steiner H, Haass C (2002) Presenilin-dependent intramembrane proteolysis of $\mathrm{CD} 44$ leads to the liberation of its intracellular domain and the secretion of an Abeta-like peptide. J Biol Chem 277:44754-44759.

Lee SF, Shah S, Li H, Yu C, Han W, Yu G (2002) Mammalian APH-1 interacts with presenilin and nicastrin and is required for intramembrane proteolysis of amyloid-beta precursor protein and Notch. J Biol Chem 277:45013-45019.

Li J, Fici GJ, Mao CA, Myers RL, Shuang R, Donoho GP, Pauley AM, Himes CS, Qin W, Kola I, Merchant KM, Nye JS (2003a) Positive and negative regulation of the gamma-secretase activity by nicastrin in a murine model. J Biol Chem 278:33445-33449.

Li T, Ma G, Cai H, Price DL, Wong PC (2003b) Nicastrin is required for assembly of presenilin/gamma-secretase complexes to mediate Notch signaling and for processing and trafficking of beta-amyloid precursor protein in mammals. J Neurosci 23:3272-3277.

López-Schier H, St. Johnston D (2002) Drosophila nicastrin is essential for the intramembranous cleavage of notch. Dev Cell 2:79-89.

Marambaud P, Shioi J, Serban G, Georgakopoulos A, Sarner S, Nagy V, Baki L, Wen P, Efthimiopoulos S, Shao Z, Wisniewski T, Robakis NK (2002) A presenilin-1/gamma-secretase cleavage releases the E-cadherin intracellular domain and regulates disassembly of adherens junctions. EMBO J 21:1948-1956.

Morris RG, Garrud P, Rawlins JN, O’Keefe J (1982) Place navigation impaired in rats with hippocampal lesions. Nature 297:681-683.

Murakami D, Okamoto I, Nagano O, Kawano Y, Tomita T, Iwatsubo T, De Strooper B, Yumoto E, Saya H (2003) Presenilin-dependent gammasecretase activity mediates the intramembranous cleavage of CD44. Oncogene 22:1511-1516.

Nelson O, Tu H, Lei T, Bentahir M, de Strooper B, Bezprozvanny I (2007) Familial Alzheimer disease-linked mutations specifically disrupt $\mathrm{Ca}^{2+}$ leak function of presenilin 1. J Clin Invest 117:1230-1239.

Nguyen V, Hawkins C, Bergeron C, Supala A, Huang J, Westaway D, St. George-Hyslop P, Rozmahel R (2006) Loss of nicastrin elicits an apoptotic phenotype in mouse embryos. Brain Res 1086:76-84.

Ni CY, Murphy MP, Golde TE, Carpenter G (2001) gamma-Secretase cleavage and nuclear localization of ErbB-4 receptor tyrosine kinase. Science 294:2179-2181.

Phillips RG, LeDoux JE (1992) Differential contribution of amygdala and hippocampus to cued and contextual fear conditioning. Behav Neurosci 106:274-285. 
Price DL, Tanzi RE, Borchelt DR, Sisodia SS (1998) Alzheimer's disease: genetic studies and transgenic models. Annu Rev Genetics 32:461-493.

Rutten BP, Wirths O, Van de Berg WD, Lichtenthaler SF, Vehoff J, Steinbusch HW, Korr H, Beyreuther K, Multhaup G, Bayer TA, Schmitz C (2003) No alterations of hippocampal neuronal number and synaptic bouton number in a transgenic mouse model expressing the beta-cleaved C-terminal APP fragment. Neurobiol Dis 12:110-120.

Saura CA, Choi SY, Beglopoulos V, Malkani S, Zhang D, Shankaranarayana Rao BS, Chattarii S, Kelleher RJ 3rd, Kandel ER, Duff K, Kirkwood A, Shen J (2004) Loss of presenilin function causes impairments of memory and synaptic plasticity followed by age-dependent neurodegeneration. Neuron 42:23-36.

Saura CA, Chen G, Malkani S, Choi SY, Takahashi RH, Zhang D, Gouras GK, Kirkwood A, Morris RG, Shen J (2005) Conditional inactivation of presenilin 1 prevents amyloid accumulation and temporarily rescues contextual and spatial working memory impairments in amyloid precursor protein transgenic mice. J Neurosci 25:6755-6764.

Selkoe D, Kopan R (2003) Notch and Presenilin: regulated intramembrane proteolysis links development and degeneration. Annu Rev Neurosci 26:565-597.

Shah S, Lee SF, Tabuchi K, Hao YH, Yu C, LaPlant Q, Ball H, Dann CE 3rd, Südhof T, Yu G (2005) Nicastrin functions as a gamma-secretasesubstrate receptor. Cell 122:435-447.
Shen J, Bronson RT, Chen DF, Xia W, Selkoe DJ, Tonegawa S (1997) Skeletal and CNS defects in Presenilin-1-deficient mice. Cell 89:629-639.

Steiner H, Winkler E, Edbauer D, Prokop S, Basset G, Yamasaki A, Kostka M, Haass C (2002) PEN-2 is an integral component of the gamma-secretase complex required for coordinated expression of presenilin and nicastrin. J Biol Chem 277:39062-39065.

Trojanowski JQ, Lee VM (2002) The role of tau in Alzheimer's disease. Med Clin North Am 86:615-627.

Tu H, Nelson O, Bezprozvanny A, Wang Z, Lee SF, Hao YH, Serneels L, De Strooper B, Yu G, Bezprozvanny I (2006) Presenilins form $\mathrm{ER} \mathrm{Ca}^{2+}$ leak channels, a function disrupted by familial Alzheimer's disease-linked mutations. Cell 126:981-993.

West MJ, Gundersen HJ (1990) Unbiased stereological estimation of the number of neurons in the human hippocampus. J Comp Neurol 296:1-22.

Yu G, Nishimura M, Arawaka S, Levitan D, Zhang L, Tandon A, Song YQ, Rogaeva E, Chen F, Kawarai T, Supala A, Levesque L, Yu H, Yang DS, Holmes E, Milman P, Liang Y, Zhang DM, Xu DH, Sato C, et al. (2000) Nicastrin modulates presenilin-mediated notch/glp-1 signal transduction and betaAPP processing. Nature 407:48-54.

Yu H, Saura CA, Choi SY, Sun LD, Yang X, Handler M, Kawarabayashi T, Younkin L, Fedeles B, Wilson MA, Younkin S, Kandel ER, Kirkwood A Shen J (2001) APP processing and synaptic plasticity in presenilin-1 conditional knockout mice. Neuron 31:713-726. 